\title{
Delegation of Decision-Rights for Wetlands
}

\author{
Katarina Elofsson
}

Accepted: 21 March 2011 / Published online: 10 April 2011

(C) The Author(s) 2011. This article is published with open access at Springerlink.com

\begin{abstract}
Different nutrient abatement activities jointly determine water quality. Policies are determined by governments at central and local level, implying that decisions can be affected by strategic considerations. In this article, decentralization of wetland policies is analyzed with regard to the environmental and economic consequences. A two-stage game is used to investigate strategic abatement decisions regarding nitrogen fertilizer reductions, waste water treatment plant phosphorus reductions and wetlands, assuming that wetland decision can be decentralized. It is shown that under particular circumstances, strategic consideration may imply that a central government undertakes more abatement than socially optimal, but in most cases the opposite is likely to occur. Decentralization of wetland decisions is advantageous to the central government but only benefits the local government if its wetland technology is considerably more efficient that the central government's. This paper explains why local governments often hesitate to take on additional responsibilities for environmental management, and identifies conditions under which local governments make smaller losses or even gain from delegation. The results also contribute to understanding how strategically optimal matching grants are chosen when governments only take into account their own direct costs of abatement and the central government needs to satisfy the local government's participation constraint.
\end{abstract}

Keywords Hierarchical governance $\cdot$ Nitrogen $\cdot$ Phosphorus $\cdot$ Stackelberg · Water Framework Directive · Wetlands

\section{Introduction}

Water quality policies are determined and implemented by multiple governments in different sectors and at different levels (see e.g. Lundqvist 2004). The multitude of

K. Elofsson $(\varangle)$

Department of Economics, Swedish University of Agricultural Sciences, Uppsala, Sweden

e-mail: katarina.elofsson@slu.se 
governments involved leads to difficulties in coordinating policies to achieve cost-effectiveness, and decision-makers may act strategically to pursue their own interests.

Implementation of the EU's new Water Framework Directive (WFD) should, in principle, lead to a strengthening of the regional governmental level for water management (EC 2007). The WFD requires all EU countries to assign River Basin Districts ${ }^{1}$ and associated Competent Authorities. The Competent Authorities are responsible for compilation of environmental and economic information, and development of environmental quality targets and river basin management plans. If the river basin management plans are to be enforced, the rights and responsibilities of the Competent Authorities and those of local and national governments might need to be adjusted, particularly in regard to the right to decide on policy instruments (CA 2007). This brings to the fore the need for analysis of hierarchical governance structures with regard to environmental management. Currently, responsibilities for water quality management are split between national and local governments. Decisions on policy instruments for the agricultural sector are, to a large extent, made by central governments within the context of the CAP-financed Rural Development Programs. Local governments generally have the decision-right on wastewater management and spatial planning, both of which are important for water quality management.

There is so far little evidence that policy discretion has actually been delegated within the WFD context. On the contrary, there is a tendency for damping the independence of local governments with regard to environmental policy in general, while instead increasing - on voluntary or non-voluntary basis - the delegation of centrally defined tasks to local level (Hovik 2004). These tasks are to some extent reimbursed by the central level-intergovernmental grants to local governments, earmarked for environmental purposes, constitute up to $40 \%$ of all earmarked grants in the OECD countries (Bergvall et al. 2006). Such grants could provide local governments with incentives to increase abatement to the socially optimal level in the case of interregional spillovers, or lead to the achievement of optimal outcomes if neither central nor local governments strive to maximize social net benefits (Miceli and Segerson 1999).

The relative merits of centralized and decentralized environmental policy are extensively analyzed in the literature. It has been argued that in the presence of inter-jurisdictional tax competition, local governments have incentives to set environmental standards below the optimal level (Rauscher 1995; Porter 1999), a view that has been questioned on both empirical and theoretical grounds (Wheeler 2001; Millimet 2003; Roelfsema 2007). In principle, the right to decide on policy goals should be assigned to the lowest governmental level that takes into account all costs and benefits of the policy in question (Oates and Schwab 1996; Oates 1998; Wellisch 2000). In practice, this distinction is not always easily made; for example, when a single abatement activity may jointly reduce local, regional and global pollutants (Caplan and Silva 2005). In addition, local and national governments can have different information about the benefits and costs of policies such that it would be beneficial to society to pool information from both (Andersen and Jensen 2003). The interaction between central and local governments can be an important determinant of both the decision to decentralize and the outcome of decentralization (Pierre and Peters 2000; Andersen and Jensen 2003; Demski and Sappinton 1987; Miceli and Segerson 1999). Moreover, the impact of decentralization may vary with institutional and economic conditions (Wälti 2004).

This article is based on the following observations: (i) the local government may have a cost advantage with regard to the provision of environmental benefits (d'Amato and Valentini 2008);

1 This requirement has led to the establishment of 110 River Basin Districts across the EU27 (EC 2007). 
(ii) different abatement activities can jointly determine environmental quality; (iii) interaction between central and local governments can affect the environmental and economic outcome of decentralization; and (iv) there can be institutional constraints on delegation of policy discretion.

In this paper, the particular local cost advantage with regard to wetland construction is defined and its implications are discussed in a context where, unlike in d'Amato and Valentini (2008), interactions between governmental levels are taken into account. The model developed here highlights the trade-off between the benefits of technological advantages associated with delegation on one hand, and effects of strategic decision-making on the other. Incentives for decentralization with and without intergovernmental matching grants for local abatement are investigated. The analysis is carried out with the help of a two-stage game-theoretic model. Given the complexity that arises in sequential games, numerical simulations based on reasonable data are carried out to analyze the outcome. The paper adds to existing literature on hierarchical management through the inclusion of technology interdependence between abatement measures in combination with constraints to delegation.

The remainder of the article proceeds as follows. Section 2 presents the model, Sect. 3 describes the socially optimal solution and Sect. 4 describes the sequential games. Section 5 describes the data for the simulations, and the results are given in Sect. 6. Section 7 provides a discussion on the results.

\section{The Model}

In the following a two-stage model is developed to illustrate the interdependences between central and local decisions with regard to water quality management. It is assumed that there are two different governments $i=C, L$, where $C$ denotes the central and $L$ the local government. The central government can be thought of as the national government. Assuming zero interregional spillovers between local jurisdictions, the local government can be thought of as the aggregate of all local governments in a country. ${ }^{2}$ Each of the two governments aims to maximize net benefits, given their perceptions of benefits and costs of abatement, which are explained in the following.

There are two pollutants; nitrogen and phosphorus, which contribute to impaired water quality. Reductions in nutrients to the coastal zone are denoted $R_{n}$, with $n=N, P$, where $N$ and $P$ denote nitrogen and phosphorus, respectively. Central and local governments both benefit from reduced nutrient emissions to coastal waters. They are assumed to have identical linear benefit functions $B\left(R_{n}\right)=\sum_{n} b_{n} R_{n}$, where $b_{n}$ is the marginal benefit of reductions in nutrient $n$. Identical benefit functions is a reasonable assumption when the local level is an aggregate of all local governments. In general, benefits of nitrogen and phosphorus reductions are likely to be non-separable because eutrophication is jointly determined by the inputs of the two nutrients. However, the nature of the interdependences between nitrogen and phosphorus cannot be modeled in a general manner and often, it is not possible to determine interdependences even for a specific aquifer. Therefore, much of the scientific literature assumes separability between the two nutrients with regard to eutrophication (see e.g. Nielsen et al. 2002; Håkanson et al. 2007). Where the characteristics of interdependence can be identified, it is evident that the relationship is site-specific, complex, and nonsymmetric between the two nutrients (Håkanson et al. 2007; Wulff et al. 2007). The choice of nonseparability in

\footnotetext{
${ }^{2}$ In principle, the model could also be applied when the local government is one out of multiple local governments, as long as there are no externalities between the local governments. This would only require an appropriate scaling of the local government's benefit and cost functions.
} 
this paper is explained by convenience of modeling in combination with the lack of general interdependences.

It is assumed that there are three different abatement measures, $x_{1}, x_{2}$ and $x_{3}$, that can be used to reduce nutrient emissions to coastal waters. Of those, $x_{1}$ is reduction of nitrogen fertilizers, $x_{2}$ is the area of constructed wetlands and $x_{3}$ is reduction of phosphorus emissions from wastewater treatment plants (WWTPs). These three measures are chosen because they are among the most important available options in a cost-effective policy with regard to combating nutrient loads to the Baltic Sea (Elofsson 2010a). The central government is assumed always to have the right to determine the level of fertilizer use. This assumption is motivated by the dominating role of central governments with regard to agricultural and agri-environmental policy in most countries. It is assumed that the right to decide on wetlands could be given to either the central or local government. This assumption seems reasonable considering the current split of decision-rights between central and local governments with regard to land use management. The local government is assumed to make decisions about the level of phosphorus abatement at WWTPs. Finally, the central government is assumed to decide on the level of matching grants for abatement at the local level.

There are costs associated with the abatement measures. Cost functions are assumed to be increasing and convex and each governmental level is assumed to take into account only the costs associated with abatement over which it has decision-rights. It is assumed that the cost for each measure equals the private costs to each government of undertaking the measure in question. This assumption is motivated by agricultural policy measures and municipal wastewater treatment usually being financed by public funds. ${ }^{3}$ Ignorance with regard to costs incurred by other governmental levels could be explained by governments making a narrow ex-ante analysis of the consequences of their decisions, taking into account only direct costs. ${ }^{4}$

Cost functions differ depending on which level of government has the final decision rights on wetlands. In the case where the central government has the final say on wetlands development policy, its costs are defined by $C^{C}=a_{1}\left(x_{1}\right)^{2}+a_{2}\left(x_{2}^{C}\right)^{2}+\beta a_{3}\left(x_{3}\right)^{2}$, where $a_{1}, a_{1}$ and $a_{3}$ are cost coefficients for the different measures, respectively. This implies that the central government incurs the full cost for reductions in fertilizer use and wetlands and a fraction $\beta$, with $0 \leq \beta \leq 1$, of the costs for phosphorus reductions in WWTPs, where $\beta$ equals the matching grant for phosphorus reductions. If the local government decides on wetlands, the central government's cost function is defined by $C^{C}=a_{1}\left(x_{1}\right)^{2}+\alpha a_{2}\left(x_{2}^{L}\right)^{2}+\beta a_{3}\left(x_{3}\right)^{2}$, where $\alpha$, with $0 \leq \alpha \leq 1$, is the matching grant for wetlands. Correspondingly, the local government's cost function is defined by $C^{L}=(1-\beta) a_{3}\left(x_{3}\right)^{2}$ in the case when the central government decides on wetlands and $C^{L}=(1-\alpha) a_{2}\left(x_{2}^{L}\right)^{2}+(1-\beta) a_{3}\left(x_{3}\right)^{2}$ when the local government decides on wetlands.

\footnotetext{
3 The assumption seems reasonable as under the Rural Development Programs, countries are only allowed to compensate farmers for the direct costs incurred. For wetlands, this includes compensation for the opportunity cost of land. We note that several European countries, e.g. Sweden, Norway, Finland and Austria, have earlier controlled nitrogen fertilizer use through the use of environmental taxes, see e.g. Söderholm and Christiernsson (2008). In all cases, the tax has been revoked, suggesting that the "polluter pays" principle is not accepted for abatement in the agricultural sector.

${ }^{4}$ It is not difficult to find examples that show governments have a simplified view on the costs associated with abatement measures. For example, in a Swedish evaluation of the nitrogen fertilizer tax, cost estimates are based on a static evaluation of the farmer's costs without recognition of production adjustment possibilities, indirect costs imposed on other sectors, or indirect effects on other abatement measures (MOF 2003). For the Swedish rural development program (MOA 2008), the flat-rate level of agri-environmental support to nutrient reducing measures is calculated on the basis of private cost to an "average" Swedish farm, ignoring cost variation among farmers and production adjustment possibilities.
} 
Reductions of nitrogen and phosphorus loads to coastal waters due to reductions in nitrogen fertilizers and phosphorus reductions at WWTPs are defined by $r_{N D} x_{1}$ and $r_{P D} x_{3}$, respectively, where $r_{n D}$, with $0 \leq r_{n D} \leq 1$ equals one minus retention of nutrient $n$ on the way from the sources through the drainage basin to the coastal area. ${ }^{5}$ Thus, $r_{n D}$ expresses the impact of a unit reduction of nutrient $n$ on coastal load.

Wetlands are known to serve as sinks for nitrogen and phosphorus, and nutrient abatement in wetlands, measured in absolute terms, is increasing in the nutrient load reaching the wetland (Correll et al. 1992; Jansson et al. 1994; Svensson et al. 2004). Empirical evidence suggests that nutrient removal is lower in wetlands created with centrally rather than locally administered abatement policies. In an evaluation initiated by the Swedish Environmental Protection Agency (SEPA), wetlands constructed with the support of the centrally administered CAP-financed agri-environmental program were compared with those created under the so called Local Investment Programs (LIP), where municipalities chose the design and location of the wetlands (Svensson et al. 2004). Agri-environmental support is distributed to farmers through the national Board of Agriculture, and general rules govern the eligibility for and level of support, not including any requirements for the location of the wetland apart from being located on agricultural land. Municipalities were eligible to apply for LIP-support from the Swedish Environmental Protection Agency (SEPA) between 1998 and 2008. These applications include a plan for the location of the wetlands, and wetlands could be located also on non-agricultural land. The SEPA evaluation revealed that wetlands constructed with LIP-support abated considerably more nutrients per hectare than those constructed with CAP-support. This is explained by the LIP-wetlands being located such that their drainage area is larger and hence a large nutrient load reaches the wetland. ${ }^{6}$ This comes at a slightly higher cost. Differences in nutrient abatement seem to be explained by differences in policy instrument design, where the design of wetlands plays a minor role for the granting of the nationally administered CAP-support to farmers and a larger role for the granting of LIP-support to local municipalities (Svensson et al. 2004). Moreover, the local government has superior knowledge about the local landscape, implying that it is able to identify better locations for wetlands than the central government is. Therefore, it is here assumed that wetlands constructed by the local government abate more nutrients than those constructed by the central government because they capture a larger fraction of the total load of nutrients, i.e. they have a larger drainage area.

Nutrient abatement in coastal wetlands is then defined as $x_{2}^{i} k_{n}^{i} r_{n W}\left(L_{n}^{0}-r_{n D} x_{1}\right)$, where $k_{n}^{i}$ is the fraction of the load of nutrient $n$ entering one hectare of wetland, $r_{n W}$, with $0 \leq r_{n W} \leq 1$, is the retention of nutrient $n$ in wetlands, measured in percent, and $L_{n}^{0}$ is the initial load of nutrient $n$ reaching the coastal region. Thus, it is assumed here that wetlands remove a constant fraction of the nutrients entering the wetland and that nutrient abatement is higher when the local government chooses the design, because each unit of wetland captures a larger fraction of the nutrient load, i.e. $k_{n}^{L}>k_{n}^{C}$. It is assumed that wetlands can be constructed only in the coastal zone and once nutrients have passed the wetland, they directly enter coastal waters.

\footnotetext{
5 Nutrient retention is a process where a fraction of the nutrients emitted from the sources are captured in soils, sediments and vegetation.

6 Notably, wetlands are valuable not only because of their nutrient sink capacity but also because of their contribution to biodiversity. The SEPA report shows there is larger stated focus on nutrient reductions for wetlands constructed with LIP-support compared with those constructed with CAP-support, but there is no evidence that either type performs better with regard to biodiversity.
} 
The total reductions of nutrient loads to coastal waters are then defined by $R_{N}\left(x_{1}, x_{2}^{i}\right)=$ $x_{2}^{i} k_{N}^{i} r_{N W}\left(L_{N}^{0}-r_{N D} x_{1}\right)+r_{N D} x_{1}$ and $R_{P}\left(x_{2}^{i}, x_{3}\right)=x_{2}^{i} k_{P}^{i} r_{P W}\left(L_{P}^{0}-r_{P D} x_{3}\right)+r_{P D} x_{3}$ for nitrogen and phosphorus, respectively. These functions are increasing, concave and non-separable. Nitrogen reductions depend jointly on $x_{1}$ and $x_{2}^{i}$, and phosphorus reductions depend jointly on $x_{2}^{i}$ and $x_{3}$.

The central and local governments are assumed to take their decisions sequentially with the central government making the first move. The assumption about the central government being the first mover is often made in models where vertical interaction between governments is investigated (cf. e.g. Andersson et al. 2004; Esteller-Moré and Solé-Ollé 2001; Fenge and Wrede 2004). Sequential decisions are a reasonable assumption if, for example, the central government is able to inform the local government about its decisions, while many small, local governments can have difficulties coordinating information. Also, many small governments might not be able to collude and challenge the central government, implying that the central government has market power that facilitates a commitment (cf. Boadway and Keen 1996). In the following, the socially optimal solution is first derived as a reference case. This is followed by a comparison of the sequential games where, in turn, the central and local governments have the overriding decision-right over wetlands.

\section{The Socially Optimal Solution}

Before turning to the above-described strategic problem, the socially optimal solution is first derived as a reference case. The social problem is one of maximizing total net benefits, $T N B$, of abatement, and the social optimum is one where the local government's superior knowledge about wetland technology is utilized:

$$
\begin{aligned}
\max _{x_{1}, x_{2}, x_{3}} T N B= & B\left(R_{n}\right)-C=b_{N}\left[x_{2} k_{N}^{L} r_{N W}\left(L_{N}^{0}-r_{N D} x_{1}\right)+r_{N D} x_{1}\right] \\
& +b_{P}\left[x_{2} k_{P}^{L} r_{P W}\left(L_{P}^{0}-r_{P D} x_{3}\right)+r_{P D} x_{3}\right] \\
& -a_{11}\left(x_{1}\right)^{2}-a_{2}\left(x_{2}^{i}\right)^{2}-a_{3}\left(x_{3}\right)^{2}
\end{aligned}
$$

Assuming an interior solution, the first-order conditions (FOCs) are:

$$
\begin{gathered}
b_{N}\left[-x_{2} k_{N}^{L} r_{N W} r_{N D}+r_{N D}\right]=2 a_{11} x_{1}, \\
b_{N} k_{N}^{L} r_{N W}\left(L_{N}^{0}-r_{N D} x_{1}\right)+b_{P} k_{P}^{L} r_{P W}\left(L_{P}^{0}-r_{P D} x_{3}\right)=2 a_{2} x_{2} \text { and } \\
b_{P}\left[-x_{2} k_{P}^{L} r_{P W} r_{P D}+r_{P D}\right]=2 a_{3} x_{3} .
\end{gathered}
$$

The FOCs require that marginal benefits are equated to marginal costs. The marginal benefit of $x_{1}$ and $x_{3}$ is determined by the direct impact of nitrogen fertilizer and WWTP phosphorus reductions, respectively, on coastal load minus the negative impact on wetland nutrient abatement, see Eqs. (2) and (4). Thus, the optimal level of abatement of fertilizers and wastewater emissions is smaller than if the impact on wetland abatement was ignored. Equation (3) requires that marginal benefits of wetland construction are equal to marginal costs, given that marginal benefits are determined by the load of nutrients reaching the wetland. 


\section{The Sequential Game}

If, instead, there are two different governmental levels and governments only take their own costs into account, this will affect abatement choices. A sequential game where the central government decides on wetlands is first analyzed in Sect. 4.1, followed by one where the local government has the decision-right in Sect. 4.2.

\subsection{The Central Government has the Decision-Right on Wetlands}

Assume that the central government has the decision right on $x_{1}, x_{2}$ and $\beta$, and that decisions are taken sequentially, implying that the central government will internalize the reaction of the local government. Solving the game by backwards induction, we first look at the local government's decision problem, which is as follows:

$$
\begin{aligned}
\max _{x_{3}} T N B^{L}= & B^{L}\left(R_{n}\right)-C^{L}=b_{N}\left[x_{2}^{L} k_{N}^{L} r_{N W}\left(L_{N}^{0}-r_{N D} x_{1}\right)+r_{N D} x_{1}\right] \\
& +b_{P}\left[x_{2}^{L} k_{P}^{L} r_{P W}\left(L_{P}^{0}-r_{P D} x_{3}\right)+r_{P D} x_{3}\right] \\
& -(1-\alpha) a_{2}\left(x_{2}^{L}\right)^{2}-(1-\beta) a_{3}\left(x_{3}\right)^{2}
\end{aligned}
$$

The FOC for $x_{3}$ is determined by:

$$
b_{P}\left[-x_{2}^{L} k_{P}^{L} r_{P W} r_{P D}+r_{P D}\right]=2(1-\beta) a_{3} x_{3} .
$$

The local government's reaction function, $x_{3}^{R}=x_{3}\left(x_{2}^{C}\right)$, given by Eq. (6), now enters the central government's decision-problem, where the central government strives to maximize $T N B^{C}$ subject to the local government's participation constraint:

$$
\begin{aligned}
\max _{x_{1}, x_{2}^{C}, \beta} T N B^{C}= & B\left(R_{n}\right)-C=b_{N}\left[x_{2}^{C} k_{N}^{C} r_{N W}\left(L_{N}^{0}-r_{N D} x_{1}\right)+r_{N D} x_{1}\right] \\
& +b_{P}\left[x_{2}^{C} k_{P}^{C} r_{P W}\left(L_{P}^{0}-r_{P D} x_{3}^{R}\right)+r_{P D} x_{3}^{R}\right] \\
& -a_{11}\left(x_{1}\right)^{2}-a_{2}\left(x_{2}^{C}\right)^{2}-\beta a_{3}\left(x_{3}^{R}\right)^{2}
\end{aligned}
$$

s.t.

$$
T N B^{L} \geq \underline{T N B}^{L}
$$

where $T N B^{L}$ is the level of minimum net benefits required by the local government. The size of $\underline{T N B}^{L}$ could, for example, reflect the bargaining power of the local government. If the bargaining power is low, $\underline{T N B}^{L}$ is small, and if the bargaining power is high, $\underline{T N B}^{L}$ is large.

Assuming an interior solution, the FOC for $x_{1}$ is:

$$
b_{N}\left[-x_{2} k_{N}^{L} r_{N W} r_{N D}+r_{N D}\right]=2 a_{11} x_{1}+\lambda \frac{\partial T N B^{L}}{\partial x_{1}},
$$


where $\lambda$ is the Lagrangian multiplier with regard to the participation constraint. The FOC for $x_{2}^{C}$ is:

$$
\begin{aligned}
b_{N} k_{N}^{C} r_{N W}\left(L_{N}^{0}-r_{N D} x_{1}\right) \\
+b_{P}\left[k_{P}^{C} r_{P W}\left(L_{P}^{0}-r_{P D} x_{3}^{R}\right)-x_{2}^{C} k_{P}^{C} r_{P W} r_{P D} \frac{\partial x_{3}^{R}}{\partial x_{2}^{C}}+r_{P D} \frac{\partial x_{3}^{R}}{\partial x_{2}^{C}}\right] \\
=2 a_{2} x_{2}^{C}+2 \beta a_{2} x_{3}^{R} \frac{\partial x_{3}^{R}}{\partial x_{2}^{C}}+\lambda \frac{\partial T N B^{L}}{\partial x_{2}^{C}} .
\end{aligned}
$$

The FOC for $\beta$ is:

$$
b_{P}\left[-x_{2}^{C} k_{P}^{C} r_{P W} r_{P D}+r_{P D}\right] \frac{\partial x_{3}^{R}}{\partial \beta}=a_{3}\left(x_{3}^{R}\right)^{2}+2 \beta a_{3} x_{3}^{R}+\lambda \frac{\partial T N B^{L}}{\partial \beta} .
$$

It is assumed that the problem is convex and that there is a unique point $\left(x_{1}^{*}, x_{2}^{C *}, \beta^{*}\right)$, which satisfies the problem. ${ }^{7}$

As indicated by Eq. (9), the central government's choice of $x_{2}$ is affected in several ways by the introduction of strategic decision-making compared with the socially optimal outcome. It can first be noted that the reaction function is downward sloping: $\frac{\partial x_{3}^{R}}{\partial x_{2}^{C}}=-\frac{b_{P} k_{P}^{C} r_{P W} r_{P D}}{2(1-\beta) a_{3}} \leq 0$. The central government anticipates that the local government will compensate for a higher $x_{2}$ through a decrease in $x_{3}$. Looking at the simplified case where $k_{P}^{C}=k_{P}^{L}$, it can be seen that the central government's perceived marginal benefits from an increase in $x_{2}$ will be lower than the social marginal benefit due to a direct effect of strategic decision-making. This is reflected by last term within the squared brackets in Eq. (9), $r_{P D} \frac{\partial x_{3}^{R}}{\partial x_{2}^{C}}$, which is negative. However, this will be counteracted through the technology interdependence effect, captured in the positive term $-k_{P}^{C} r_{P W} x_{2} r_{P D} \frac{\partial x_{3}^{R}}{\partial x_{2}^{C}}$, which tells us that the central government will anticipate that marginal phosphorus abatement in wetlands will increase when $x_{3}$ is reduced. The direct effect will exceed the indirect technology effect in size if $\left|k_{P}^{C} r_{P W} x_{2}\right|<1$, which holds if wetlands are modestly efficient in phosphorus abatement, but may not do so if wetlands are highly efficient in abatement. ${ }^{8}$ Thus, if wetlands are highly efficient, sequential decision-making could imply that a larger wetland area is created by the central government than socially optimal, ${ }^{9}$ while the opposite would occur if wetlands are less efficient. Turning to Eq. (10), it states that the marginal change in the environmental benefits from $x_{3}$ due to a marginal change in $\beta$ must equal the marginal cost of the change in $\beta$, taking into account the reaction of the local government with regard to its choice of $x_{3}$. Finally, comparing Eqs. (8)-(10), reveals that an increase in $\underline{T N B}^{L}$ would imply that the central government increases $x_{1}, x_{2}^{C}$ and/or $\beta$. Thus, either of the central government's decision variables could be used to satisfy the participation constraint.

\footnotetext{
7 If the problem is not convex, the FOCs are necessary but not sufficient for a global maximum. The assumption about an interior solution is made to simplify the expressions, although corner solutions where one or more of the choice variables take on either a zero or a maximum value may well occur in reality and are allowed for in the simulations below.

${ }^{8}$ If wetlands are highly efficient, $k_{P}^{C}$ and $r_{P W}$ are high, implying that $x_{2}$ is also high, while the opposite holds if wetlands are little efficient. For most real-world situations, $k_{P}^{C}$ should be a very small number, implying that that $\left|k_{P}^{C} r_{P W} x_{2}\right|<1$.

${ }^{9}$ At least this could be the outcome if the last term on the r.h.s., $\lambda \partial T N B^{L} / \partial x_{2}^{C}$, is small.
} 
4.2 The Local Government has the Final Decision-Rights on Wetlands

Next, we look at the subgame perfect outcome when the local government is given the right to decide on $x_{2}$. In this case, the local government solves the following:

$$
\begin{aligned}
\max _{x_{2}^{L}, x_{3}} T N B^{L}= & B^{L}\left(R_{n}\right)-C^{L} \\
= & b_{N}\left[x_{2}^{L} k_{N}^{L} r_{N W}\left(L_{N}^{0}-r_{N D} x_{1}\right)+r_{N D} x_{1}\right] \\
& +b_{P}\left[x_{2}^{L} k_{P}^{L} r_{P W}\left(L_{P}^{0}-r_{P D} x_{3}\right)+r_{P D} x_{3}\right] \\
& -(1-\alpha) a_{2}\left(x_{2}^{L}\right)^{2}-(1-\beta) a_{3}\left(x_{3}\right)^{2}
\end{aligned}
$$

The reaction function for $x_{2}^{L}$, is:

$$
b_{N} k_{N}^{L} r_{N W}\left(L_{N}^{0}-r_{N D} x_{1}\right)+b_{P} k_{P}^{L} r_{P W}\left(L_{P}^{0}-r_{P D} x_{3}\right)=2(1-\alpha) a_{2} x_{2}^{L},
$$

whereas the reaction function for $x_{3}$ is still defined by Eq. (6) above.

The local government's reaction functions, $x_{2}^{R}=x_{2}\left(x_{1}, \alpha, x_{3}(\beta)\right)$, given by Eq. (12) and $x_{3}^{R}=x_{3}\left(x_{2}\left(x_{1}, \alpha\right), \beta\right)$, given by Eqs. (6) and (12), now enter the decision problem. The slopes of the reaction functions with regard to $x_{1}$ are $\frac{\partial x_{2}^{R}}{\partial x_{1}}=-\frac{b_{N} k_{N}^{L} r_{N W} r_{N D}}{2(1-\alpha) a_{2}} \leq 0$ and $\frac{\partial x_{3}^{R}}{\partial x_{1}}=\frac{\partial x_{3}^{R}}{\partial x_{2}^{L}} \frac{\partial x_{2}^{L}}{\partial x_{1}}=\left[\frac{\sum_{n} b_{n} k_{n}^{L} r_{n W} r_{n D}}{4(1-\alpha)(1-\beta) a_{2} a_{3}}\right] \geq 0$. The difference in sign of the slopes is explained by fertilizer reductions and WWTP reductions both being substitutes for wetlands. The sign of the slope in the former case is explained by an increase in the wetland area being substituted for a decrease in fertilizer reductions. In the latter case, the sign of the slope is explained by an increase in the wetland area being substituted for a decrease in fertilizer reductions, and the larger wetlands area being compensated for through a smaller WWTP reduction. The slopes of the reaction functions with regard to $\alpha$ and $\beta$ are, respectively, $\frac{\partial x_{2}^{L}}{\partial \alpha} \geq 0, \frac{\partial x_{3}}{\partial \beta} \geq 0, \frac{\partial x_{3}}{\partial \alpha}=\frac{\partial x_{3}}{\partial x_{2}^{L}} \frac{\partial x_{2}^{L}}{\partial \alpha} \leq 0$ and $\frac{\partial x_{2}^{L}}{\partial \beta}=\frac{\partial x_{2}^{L}}{\partial x_{3}} \frac{\partial x_{3}}{\partial \beta} \leq 0$. That is, a higher grant tends to increase the amount of the targeted abatement measure and reduce the level of the other measure.

Knowing this, we can turn to the central government's decision problem which is to:

$$
\begin{aligned}
\max _{x_{1}, \alpha, \beta} T N B^{C}= & B\left(R_{n}\right)-C \\
= & b_{N}\left[x_{2}^{R} k_{N}^{L} r_{N W}\left(L_{N}^{0}-r_{N D} x_{1}\right)+r_{N D} x_{1}\right] \\
& +b_{P}\left[x_{2}^{R} k_{P}^{L} r_{P W}\left(L_{P}^{0}-r_{P D} x_{3}^{R}\right)+r_{P D} x_{3}^{R}\right] \\
& -a_{1}\left(x_{1}\right)^{2}-\alpha a_{2}\left(x_{2}^{R}\right)^{2}-\beta a_{3}\left(x_{3}^{R}\right)^{2}
\end{aligned}
$$

s.t.

$$
T N B^{L} \geq \underline{T N B}^{L}
$$


The FOC for $x_{1}$ as follows:

$$
\begin{aligned}
& b_{N}\left[\frac{\partial x_{2}^{R}}{\partial x_{1}} k_{N}^{L} r_{N W}\left(L_{N}^{0}-r_{N D} x_{1}\right)-x_{2}^{R} k_{N}^{L} r_{N W} r_{N D}+r_{N D}\right] \\
& +b_{P}\left[\frac{\partial x_{2}^{R}}{\partial x_{1}} k_{P}^{L} r_{P W}\left(L_{P}^{0}-r_{P D} x_{3}^{R}\right)-x_{2}^{R} k_{P}^{L} r_{P W} r_{P D} \frac{\partial x_{3}^{R}}{\partial x_{1}}+r_{P D} \frac{\partial x_{3}^{R}}{\partial x_{1}}\right] \\
& =2 a_{1} x_{1}+2 \alpha a_{2} x_{2} \frac{\partial x_{2}^{R}}{\partial x_{1}}+2 \beta a_{3} x_{3} \frac{\partial x_{3}^{R}}{\partial x_{1}}+\lambda \frac{\partial T N B^{L}}{\partial x_{1}}
\end{aligned}
$$

Comparing this with the corresponding FOC for the socially optimal solution in Eq. (2), there are several differences. When decisions are taken strategically, the central government will take into account that an increase in $x_{1}$ will imply that the local government reduces $x_{2}^{L}$. Thereby, benefits from wetland nutrient abatement are reduced, as shown in the negative terms $\frac{\partial x_{2}^{R}}{\partial x_{1}} k_{N}^{L} r_{N W}\left(L_{N}^{0}-r_{N D} x_{1}\right)$ and $\frac{\partial x_{2}^{R}}{\partial x_{1}} k_{P}^{L} r_{P W}\left(L_{P}^{0}-r_{P D} x_{3}^{R}\right)$. However, the central government will anticipate that there will also be a secondary impact on the local government's choice of $x_{3}$, which will increase. This is associated with an increase in the central government's marginal net benefit owing to the direct effect on abatement, but has the disadvantage that the wetland phosphorus abatement will fall. The additional terms on the 1.h.s., compared with Eq. (2), will all be negative except $r_{P D} \frac{\partial x_{3}^{R}}{\partial x_{1}}$, i.e. the direct effect on abatement, which is positive. Thus, if $x_{3}$ was not included in the problem, $x_{1}$ would definitely be smaller under sequential decision-making where the local government decides on wetlands. Moreover, all the negative additional terms will include $\left(k_{n}^{L}\right)^{2}$, whereas the positive term, $r_{P D} \frac{\partial x_{3}^{R}}{\partial x_{1}}$, includes only $k_{P}^{L}$. Given that $k_{n}^{L}$ is a small term, we can therefore not exclude the possibility that $x_{1}$ is larger under sequential decision-making than is socially optimal. This is more likely if $k_{n}^{L}$ is small. With positive matching grants, the central government saves on costs for grants to wetlands by increasing $x_{1}$ but has to spend more on grants for phosphorus reductions at WWTPs.

Matching grants are determined in a strategically optimal way and the FOC for $\alpha$ is as follows:

$$
\begin{aligned}
& \sum_{n}\left(b_{n} k_{n}^{L} r_{n W} L_{n}^{0}\right) \frac{\partial x_{2}^{R}}{\partial \alpha}+b_{P}\left[-k_{P}^{L} r_{P W} r_{P D}\left(\frac{\partial x_{2}^{R}}{\partial \alpha} x_{3}^{R}+\frac{\partial x_{3}^{R}}{\partial \alpha} x_{2}^{R}\right)+r_{P D} \frac{\partial x_{3}^{R}}{\partial \alpha}\right] \\
& =a_{2}\left(x_{2}^{R}\right)^{2}+2 \alpha a_{2} x_{2}^{R} \frac{\partial x_{2}^{R}}{\partial \alpha}+2 \beta a_{3} x_{3}^{R} \frac{\partial x_{3}^{R}}{\partial \alpha}+\lambda \frac{\partial T N B^{L}}{\partial \alpha}
\end{aligned}
$$

The first term on the 1.h.s. in Eq. (15) is the direct impact of a larger $\alpha$ on benefits of wetland nutrient abatement. The first term within squared brackets expresses the joint effects on wetland phosphorus abatement from changes in both $x_{2}^{L}$ and $x_{3}$ due to a marginal increase in $\alpha$, while the last term expresses the direct effect on phosphorus abatement. On the right hand side, we have the marginal change in costs when $\alpha$ is increased, determined by optimal levels of $x_{2}^{L}$ and $x_{3}$ and the marginal changes in those. 
The FOC for $\beta$ is:

$$
\begin{aligned}
& b_{N} k_{N}^{L} r_{N W}\left(L_{N}^{0}-r_{N D} x_{1}\right) \frac{\partial x_{2}^{R}}{\partial \beta} \\
& +b_{P}\left[k_{P}^{L} r_{P W}\left(\frac{\partial x_{2}^{R}}{\partial \beta}\left(L_{P}^{0}-r_{P D} x_{3}^{R}\right)-x_{2}^{R} r_{P D} \frac{\partial x_{3}^{R}}{\partial \beta}\right)+r_{P D} \frac{\partial x_{3}^{R}}{\partial \beta}\right] \\
& =2 \alpha a_{2} x_{2}^{R} \frac{\partial x_{2}^{R}}{\partial \beta}+a_{3}\left(x_{3}^{R}\right)^{2}+\beta a_{3} x_{3}^{R} \frac{\partial x_{3}^{R}}{\partial \beta}+\lambda \frac{\partial T N B^{L}}{\partial \beta},
\end{aligned}
$$

which can be interpreted in a similar manner as for Eq. (15).

The analysis above shows that abatement carried out and the associated net benefits will be jointly determined by the allocation of decision-rights for wetlands, the technological interdependence between wetlands and other measures, and the choice of intergovernmental matching grants. However, the direction of the impact also depends on the difference in wetland technologies adopted by central and local governments. Hence, the consequences of delegation can only be judged with the help of empirical data. To analyze the implications of delegation on abatement choices, grants and net benefits, we use simulations based on realistic data.

\section{Data}

Data for the simulations for Sweden have been obtained from the literature. Benefits are assumed to be linear in nutrient load reductions. Following Mäler (1989), marginal benefits are derived from observed policies, assuming that policy-makers equate marginal cost and marginal benefit. Using the model in Elofsson (2010b), the marginal costs for nitrogen and phosphorus reductions undertaken in Sweden between 1995 and 2005 were estimated to be 33 and 101 EUR, respectively, per kilo of nutrient reaching coastal waters. This is assumed to equal the marginal benefit of nutrient reductions.

The cost of nitrogen fertilizer reductions is the reduction in consumer surplus in the nitrogen fertilizer market, while the cost for wetland construction is the sum of construction costs and compensation for the opportunity costs for land. Costs for WWTP phosphorus reductions are the costs of increasing abatement capacity in WWTPs. For all measures, quadratic cost functions are calculated from data in Gren et al. (2008). On the basis of data in Svensson et al. (2004), local government wetland construction costs are assumed to be 2.6 times higher than those of the central government. ${ }^{10}$

The impact of nitrogen fertilizer reductions on coastal loads is determined by nutrient root zone leaching and retention of nutrients in inland waters. The impact of a reduction of phosphorus loads from WWTPs is determined by phosphorus retention in inland waters. The parameter $r_{n D}$ is calculated based on information on these data in Gren et al. (2008). Wetlands reduce both nitrogen and phosphorus loads. The parameters $k_{r}^{i}$ and $r_{n W}$ are calculated from data in Svensson et al. (2004), while assuming that parameters associated with wetlands constructed with the help of agri-environmental (CAP) support are relevant for the central government, while parameters for LIP wetlands are relevant for the local government. Given this assumption, data suggest that locally designed wetlands capture on average 18 times more nitrogen and 11 times more phosphorus than centrally designed wetlands. Initial

10 This cost difference is not explicitly incorporated in the theoretical model above because it is of limited theoretical interest, but is included in the simulations because of its empirical relevance. 
loads from nitrogen fertilizers and WWTP plants have been calculated using data from Statistics Sweden, and it is assumed that those are the only nutrient emission sources. It is assumed that net loads must be nonnegative.

\section{Results}

Using the above-described data, the implications of delegation are simulated using a GAMS (Rosenthal 2008) programming model. For the calculations, multiple runs are made with different initial values to control for the possibility of multiple local optima.

First, the outcome under a hypothetical, single decision-maker is calculated. This is followed by calculation of the outcome of a sequential game according to default parameter values and zero matching grants. The game with default parameter values is then compared with the outcome when governments are identical with regard to costs and wetland efficiency, thereby isolating the "pure" effect of strategic decision-making. These calculations show that results are highly sensitive to assumptions about the difference in wetland abatement performance between central and local governments and therefore, sensitivity analysis is carried out with regard to this difference. Finally, the possibility of applying a strategically optimal grant is introduced, and the sensitivity of the optimal grants with regard to different values of $k_{r}^{L}$ and $\underline{T N B}^{L}$ is investigated.

\subsection{A Single Decision-Maker}

The outcome with a single decision-maker is first calculated using default values, see the left part of Table 1. These calculations show that if the central government makes all decisions, all abatement measures are used, but if the local government makes all decisions there will be a corner solution where wetland construction is the only abatement measure. The latter is also the socially optimal outcome.

\subsection{Sequential Decisions}

The outcome of sequential decision-making is first investigated for the case with zero matching grants. Results are shown in Table 1. The third and fourth columns in the table show results for default parameters values. If the central government decides on wetlands this implies that fertilizer reductions are increased, and wetland construction is reduced compared with the socially optimal outcome. This is explained by the central government using its first-mover advantage to make the local government increase WWTP reductions. If wetland decision rights are delegated, this would imply that the socially optimal outcome is achieved, which is explained by the high effectiveness of wetlands with regard to nutrient abatement compared with other measures. This leads to a corner solution, where strategic behavior becomes zero as other measures are not used. Delegation then leads to a gain in net benefits to both governmental levels and society as a whole.

The fifth and sixth columns in Table 1 depict the outcome when governments have identical wetland effect and cost parameters, equal to the default values for the central government. In this scenario, delegation leads to increased wetland construction and smaller fertilizer reductions while WWTP reductions are unaffected, changes which are all explained by strategic decision-making. Both government levels will lose from delegation because of the larger strategic interaction in this game, compared with the one where the central 


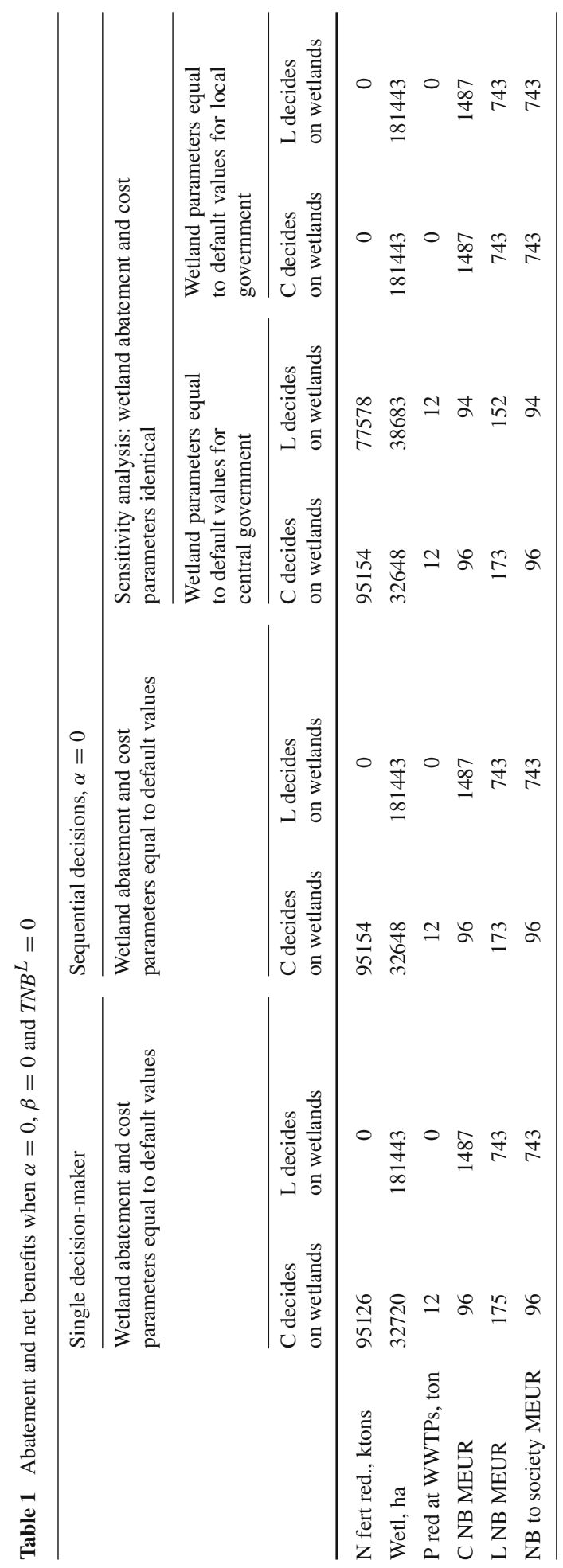


Table 2 Sensitivity analysis w.r.t. $k^{L}$ under sequential decisions when $\alpha=0, \beta=0, T N B^{L}=0$

\begin{tabular}{|c|c|c|c|c|c|c|}
\hline & $\begin{array}{l}\mathrm{C} \text { decides } \\
\text { on } \\
\text { wetlands }\end{array}$ & $\begin{array}{l}\text { L decides on } \\
\text { wetlands, } \\
k^{L}=2 k^{C}\end{array}$ & $\begin{array}{l}\text { L decides on } \\
\text { wetlands, } \\
k^{L}=4 k^{C}\end{array}$ & $\begin{array}{l}\mathrm{L} \text { decides on } \\
\text { wetlands, } \\
k^{L}=6 k^{C}\end{array}$ & $\begin{array}{l}\text { L decides on } \\
\text { wetlands, } \\
k^{L}=8 k^{C}\end{array}$ & $\begin{array}{l}\text { L decides on } \\
\text { wetlands, } \\
k^{L}=10 k^{C}\end{array}$ \\
\hline $\mathrm{N}$ fert red., ktons & 95126 & 102282 & 79661 & 2895 & 0 & 0 \\
\hline Wetl, ha & 32720 & 9572 & 23677 & 58513 & 79169 & 98961 \\
\hline $\begin{array}{l}\text { P red at WWTPs, } \\
\text { ton }\end{array}$ & 12 & 13 & 9 & 0 & 0 & 0 \\
\hline C NB, MEUR & 96 & 92 & 107 & 159 & 283 & 442 \\
\hline L NB, MEUR & 175 & 168 & 142 & 82 & 142 & 211 \\
\hline $\begin{array}{l}\text { NB to society, } \\
\text { MEUR }\end{array}$ & 96 & 89 & 94 & 82 & 142 & 211 \\
\hline
\end{tabular}

government decides on wetlands. This is explained by fertilizer and wetland decisions being more closely interlinked than wetland and WWTP decisions. In the seventh and eighth columns, the outcomes of delegation are compared when governments have identical wetland effect and cost parameters, equal to the default values for the local government. In both cases, the socially optimal outcome would be achieved, implying that strategic interaction is cancelled because wetlands are highly superior in nutrient abatement.

\subsection{Sensitivity Analysis}

The results in Table 1 reveal that the large magnitude of the difference in wetland abatement effect between local and central governments, suggested in the EPA evaluation discussed above, leads to radically different outcomes of the strategic game, depending on who decides on wetlands. Given the large difference in wetland abatement effects suggested by the EPA report, sensitivity of results to the difference between $k^{C}$ and $k^{L}$ is investigated in Table 2 for the case with zero matching grants. The calculations show that the outcome is highly sensitive to this difference. With $k^{L}=2 k^{C}$, both governments lose from delegation because of the higher cost of locally constructed wetlands. This also results in a reduction in the area of constructed wetlands and an increase in fertilizer reductions. With $k^{L} \geq 4$, the central government gains from delegation because: (i) it does not have to bear costs for wetland construction; (ii) its benefits from wetland construction are greater; and (iii) its first-mover advantage implies that more of the abatement burden is shifted over to the local government. The local government gains from decentralization if $k^{L} \geq 9$. Only above this level will the gains of greater wetland abatement efficiency outweigh the disadvantage of the higher wetland construction costs and the local government's strategically disadvantageous position. Society as a whole would only gain from delegation if $k^{L} \geq 7$, a level above which the overall strategic bias in combination with higher wetland construction costs is outweighed by higher wetland abatement efficiency. The most disadvantageous situation for the local government is when $k^{L}=6$. The explanation is that for this level of the parameter, WWTP reductions are excluded from the game, wherefore the central government no longer has any incentive to maintain high fertilizer reductions to make the local government follow with high WWTP reductions, as discussed in the theoretical section above. Instead, the central government fully exploits its strategic position to make the local government increase wetland construction. 
Thus, the inclusion of WWTP reductions in the game implies that the central government must withhold some of its power to shift the abatement burden to the local government.

In Table 3, the optimal grant is calculated for modest differences between central and local governments with regard to $k^{i} .{ }^{11}$ Grants are calculated for two different participation constraints, $T N B^{L}=0$, which is non-binding, and $T N B^{L}=175$, where the latter is chosen because it implies that the local government requires at least as high net benefits after delegation as when the central government has the decision-right on wetlands. Thus, this reflects a case where the local government has a high bargaining power, and only accepts delegation if this leads to higher net benefits than when the central government decides on wetlands. Results show that for small improvements in wetlands efficiency, $k^{L}=2 k^{C}$, the strategically optimal grants would both be around 0.3 , even when there is no binding participation constraint. Given that the participation constraint is not binding, the intuition is that the central government chooses the grants to exploit the opportunity of getting large environmental benefits at low (perceived) cost, which could for example be achieved by directing the grant to abatement with slowly increasing marginal cost. For higher $k^{L}, \beta=0$ because WWTP reductions are no longer included in the solution. With a binding participation constraint, the central government meets this by simultaneously increasing all of the parameters $\alpha, \beta$ (provided that WWTP reductions are included) and $x_{1}$. The results indicate that the central government strives to do this in a manner such that the net impact on the abatement decisions by both decision-makers is kept small, implying that the net effect comes relatively close to that of a lump-sum grant.

It may also be noted that the possibility to choose a strategically optimal grant is not beneficial for society as a whole because it increases the strategic bias compared with the socially optimal outcome and therefore, social net benefits are reduced. However, a binding participation constraint seems to limit the strategic bias in the game when $4 k^{C} \leq k^{L} \leq 6 k^{C}$, as it sets limits on the central government's use of its first-mover advantage and provides an incentive to increase $x_{1}$. Therefore, social net benefits are higher than when the constraint is non-binding. For higher levels of $k^{L}$ the participation constraint is nonbinding and both governments benefit from strategically chosen grants, as they provide environmental benefits at a perceived low cost. This has, as expected, negative social effects.

\section{Summary and Conclusions}

This article develops a model of hierarchical governance in water management, that captures several plausible characteristics of applicable the policy settings such as strategic delegation, limited scope for delegation of decision-rights, interdependence between measures with regard to the environmental effects, and strategic monetary transfers between governments at different levels.

The analysis shows that if decisions are taken sequentially and the central government moves first, i.e. there is a Stackelberg game, strategic consideration becomes an important determinant of decisions of abatement and intergovernmental grants. It is shown that with sequential decisions, the central government might undertake more abatement than socially optimal if wetlands are highly efficient in nutrient abatement. With less efficient nutrient abatement in wetlands, we have the more intuitive result that the central government will use its strategic position to shift more of the abatement burden to the local government.

11 For $8 k^{C} \leq k^{L} \leq 18 k^{C}$, grants remain constant. 


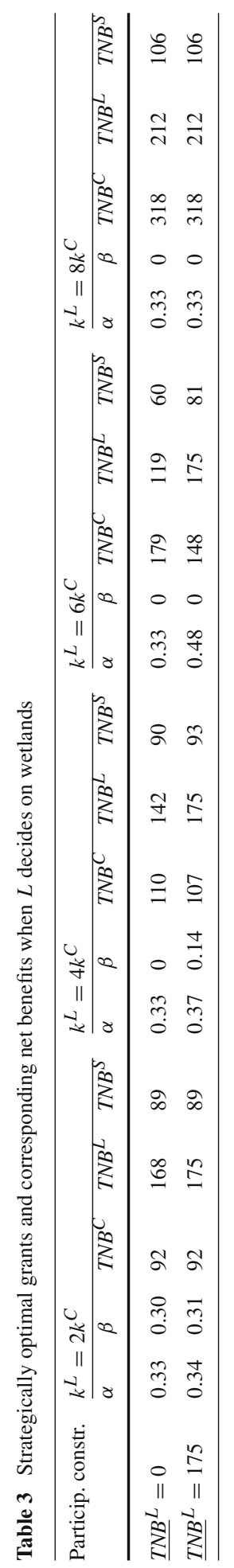


The model is simulated based on Swedish data. The simulations show that with sequential decisions where the central government explores its first mover advantage, both governments may lose from delegation if they have identical wetland technology and costs and wetland efficiency is low, because of the larger strategic bias in a game where wetland decisions are delegated to the local level. This is explained by the interdependence between nitrogen fertilizer reductions and wetlands being larger than the interdependence between wetlands and phosphorus reductions at WWTPs.

The simulations also illustrate that net benefits to each governmental level are jointly determined by costs, environmental effects, and strategic bias in the game. The central government will prefer delegation of decision-rights for wetlands already for low improvements in wetland abatement given its strategically advantageous position. The local government will be worse off under delegation unless locally designed wetlands are considerably more efficient than centrally designed, implying that strategic disadvantages are outweighed by higher technological efficiency. Two factors can dampen the central government's possibilities to exploit its strategically advantageous position: (i) larger independency of the local government; and (ii) the local government having the decision-right over WWTP phosphorus management. A larger independency, where the local government resists taking on additional decision rights unless they are associated with an increase in net benefits, implies that the central government must meet the local government's participation constraint with a combination of larger abatement efforts by the central government and higher intergovernmental grants for local abatement. The fact that the local government has the decision-right on WWTP phosphorus management implies that the central government is less inclined to make the local government increase wetland construction because of the negative effects this will have on WWTP phosphorus abatement. In most cases, these two factors will also reduce the negative social consequences of strategic behavior in this game.

Finally, simulations illustrate that strategically chosen matching grants can serve two different purposes, one of reducing the perceived costs of abatement to the central government, and one of satisfying the local government's participation constraint. The results indicate that the strategy for the choice of grants differs between the purposes. In the former case, grants are directed to measures with slowly increasing marginal cost, thereby leading to larger deviations from the socially optimal outcome. In the latter, grants are chosen such that the overall impact on abatement decisions is kept low, thereby leading to only small deviations from the socially optimal outcome. This suggests that grants with the purpose of satisfying a local government's participation constraint may have less negative consequences for society than grants aiming at reducing the central government's perceived costs of measures undertaken.

This paper investigates the outcome of a Stackelberg game. This is not to say that a Stackelberg game is the only possible type of interaction between governmental levels, but other forms of interaction, such as Cournot games, Nash bargaining, or repeated or cooperative games could be relevant for modeling determination of environmental policy. The outcome of such interaction remains to be investigated and results may differ from those presented here. Moreover, the simulations here are a stylized representation of Swedish policy and should be taken as an attempt to analyze how decisions are determined in a hierarchical setting, rather than as a basis for suggesting policy changes. One limitation of the model is that several factors, such as capacity for wetland construction at different locations, and therefore with different nutrient abatement potential, is not included in the model. In addition, as becomes clear in the analysis, the number of abatement activities and associated policy decisions included in the model affects the outcome. There are additional options available for improving water quality such as abatement at other emission sources and introduction of alternative land uses which reduce nitrogen leaching. 
The article's results offer better understanding of some of the mechanisms that govern the environmental and economic consequences of partial delegation of environmentally interlinked policy measures. They explain some of the reluctance that local governments seem to have against taking on additional responsibilities for environmental management and point to some of the factors that dampen the negative effects of strategic behavior. Our results also contribute to the understanding of why and how earmarked grants for environmental purposes are paid to local governments in the absence of interregional spillovers. Although the study is limited to dealing only with one particular land use measure-wetlands - the results could carry over also to other land use measures in their role for water management policies. The reason is that land is usually multifunctional, serving as a pollutant sink for different kinds of pollutants, while the emission sources may be regulated at both central and local levels.

Acknowledgements Helpful comments from two anonymous referees are gratefully acknowledged.

Open Access This article is distributed under the terms of the Creative Commons Attribution Noncommercial License which permits any noncommercial use, distribution, and reproduction in any medium, provided the original author(s) and source are credited.

\section{References}

Andersen P, Jensen F (2003) Local pollution in federal systems. J Environ Resour Econ 26:417-428

Andersson L, Aronsson T, Wikström M (2004) Testing for vertical fiscal externalities. Int Tax Public Finance 11:243-263

Bergvall D, Charbit C, Kraan D-J, Merk O (2006) Intergovernmental transfers and decentralised public spending. OECD J Budget 5:111-158

Boadway R, Keen MJ (1996) Efficiency and the optimal direction of federal-state transfers. Int Tax Public Finance 3:137-155

CA (2007) Redovisning av uppdrag om behov av ändringar i lagstiftning, medel, ansvarsfördelning m.m. för vattenförvaltningen, Dnr M2007/2038/Na. Competent Authorities of Sweden. Available via http:// www.vattenmyndigheterna.se/NR/rdonlyres/8D6FA5C7-7CC7-4A8D-B007-9F038D19BDBC/77714/ Reguppdrag070525_förändringaravverksamheten_slutli.doc. Cited June 23, 2008

Caplan AJ, Silva ECD (2005) An efficient mechanism to control correlated externalities: redistributive transfers and the coexistence of regional and global pollution permit markets. J Environ Econ Manage 49:68-82

Correll DL, Jordan TE, Weller DE (1992) Nutrient flux in a landscape: effects of coastal land use and terrestrial community mosaic on nutrient transport to coastal waters. Estuaries Coasts 15:431-442

d'Amato A, Valentini E (2008) Enforcement and environmental quality in a decentralized emission trading system. Note di lavoro 2008.097, Fondazione Eni Enrico Mattei, Milano

Demski J, Sappington D (1987) Hierarchical Regulatory Control. RAND J Econ 18:369-383

EC (2007) First report on the implementation of the Water Framework Directive 2000/60/EC. Commission Staff Working Document, SEC (2007) 362 final

Elofsson K (2010a) The costs of meeting the environmental objectives for the Baltic Sea: a review of the literature. Ambio 39(1):49-58

Elofsson K (2010b) Baltic-wide and Swedish Nutrient Reduction Targets: An Evaluation of Cost-effective Strategies. Expertgruppen för Miljöstudier (Expert Group for Environmental Studies), Ministry of Finance, Stockholm

Esteller-Moré Á, Solé-Ollé A (2001) Vertical income tax externalities and fiscal interdependence: evidence from the US. Reg Sci Urban Econ 31(2-3):247-272

Fenge R, Wrede M (2004) EU regional policy. Vertical fiscal externalities and matching grants. CESifo Working Paper No. 1146

Gren IM, Jonzon Y, Lindqvist M (2008) Costs of nutrient reductions to the Baltic Sea-technical report. Working paper 2008: 1, Department of Economics, Swedish University of Agricultural Sciences, Uppsala

Håkanson L, Bryhn A, Eklund J (2007) Modelling phosphorus and suspended particulate matter in Ringkøbing Fjord in order to understand regime shifts. J Mar Syst 68(1):65-90 
Hovik S, Reitan M (2004) National environmental goals in search of local institutions. Environ Plan C Govn Policy 22:687-699

Jansson M, Andersson R, Berggren H, Leonardson L (1994) Wetlands as lakes and nitrogen traps. Ambio 23:320-325

Lundqvist LJ (2004) Integrating Swedish water resource management: a multi-level governance trilemma. Local Environ 9:413-424

Mäler KG (1989) The acid rain game. In: Folmer H, van Ierland E (eds) Valuation methods and policy making in environmental economics. Elsevier Science Publishers B.V, Amsterdam

Miceli T, Segerson K (1999) Threshold rules for funding environmental mandates: accountability and the unfunded mandate reform act. Land Econ 75(3):375-389

Millimet DL (2003) Assessing the empirical impact of environmental federalism. J Reg Sci 43:1-23

MOA (2008) Rural development programme for Sweden. Ministry of Agriculture, Stockholm

MOF (2003) Taxes on fertilizers and pesticides? [In Swedish] SOU 2003:9. Ministry of Finance, Stockholm

Nielsen SL, Sand-Jensen K, Borum J, Geertz-Hansen O (2002) Phytoplankton, nutrients, and transparency in Danish coastal waters. Estuar Coasts 25(5):930-937

Oates WE (1998) The economics of fiscal federalism and local finance. Elgar, Cheltenham

Oates WE, Schwab RM (1988) Economic competition among jurisdictions: efficiency enhancing or distortion inducing? J Public Econ 35:333-354

Oates W, Schwab R (1996) The theory of regulatory federalism: the case of environmental management. In: Oates W (ed) The economics of environmental regulation. Elgar, Aldershot, pp 319-331

Pierre J, Peters BG (2000) Governance, politics and the state. Macmillan, London

Porter G (1999) Trade competition and pollution standards: race to the bottom or stuck at the bottom? J Environ Dev 8:133-151

Rauscher M (1995) Environmental regulation and the location of polluting industries. J Int Tax Public Finance 2:229-244

Roelfsema H (2007) Strategic delegation of environmental policy making. J Environ Econ Manage 53: $270-275$

Rosenthal RE (2008) GAMS—a user's guide. Washington DC: GAMS Development Corporation, 2008. Available via http://www.gams.com/dd/docs/bigdocs/GAMSUsersGuide.pdf. Cited 30th January 2009

Söderholm P, Christiernsson A (2008) Policy effectiveness and acceptance in the taxation of environmentally damaging chemical compounds. Environ Sci Policy 11:240-252

Svensson JM, Strand J, Sahlén G, Weisner S (2004) Rikare mångfald och mindre kväve. Utvärdering av våtmarker skapade med stöd av lokala investeringsprogram och landsbygdsutvecklingsstöd. Report 5362, Environmental Protection Agency, Stockholm

Wälti S (2004) How multilevel structures affect environmental policy in industrialized countries. Eur J Polit Res 43:599-634

Wellisch D (2000) Theory of public finance in a federal state. Cambridge University Press, Cambridge

Wheeler D (2001) Racing to the bottom? Foreign investment and air pollution in developing countries. J Environ Dev 10:225-245

Wulff F, Savchuk OP, Sokolov A, Humborg C, Mörth CM (2007) Management options and effects on a marine ecosystem: assessing the future of the baltic. AMBIO: J Hum Environ 36(2):243-249 